\title{
Study on the Optical Properties of Triangular Cavity Absorber for Parabolic Trough Solar Concentrator
}

\author{
Fei Chen, ${ }^{1}$ Ming Li, ${ }^{1}$ Reda Hassanien Emam Hassanien, ${ }^{1}$ Xi Luo, ${ }^{1}$ Yongrui Hong, \\ Zhikang Feng, ${ }^{2}$ Mengen $\mathrm{Ji}^{2}{ }^{2}$ and Peng Zhang ${ }^{3}$ \\ ${ }^{1}$ Solar Energy Research Institute, Yunnan Normal University, Kunming 650500, China \\ ${ }^{2}$ School of Physics and Electronic Information, Yunnan Normal University, Kunming 650500, China \\ ${ }^{3}$ Institute of Refrigeration and Cryogenics, MOE Key Laboratory for Power Machinery and Engineering, Shanghai Jiao Tong University, \\ Shanghai 200240, China
}

Correspondence should be addressed to Ming Li; limingse@163.com

Received 15 May 2015; Revised 1 August 2015; Accepted 4 August 2015

Academic Editor: Mahmoud M. El-Nahass

Copyright (C) 2015 Fei Chen et al. This is an open access article distributed under the Creative Commons Attribution License, which permits unrestricted use, distribution, and reproduction in any medium, provided the original work is properly cited.

\begin{abstract}
A theoretical analytical method for optical properties of cavity absorber was proposed in this paper and the optical design software TracePro was used to analyze the optical properties of triangular cavity absorber. It was found that the optimal optical properties could be achieved with appropriate aperture width, depth-to-width ratio, and offset distance from focus of triangular cavity absorber. Based on the results of orthogonal experiment, the optimized triangular cavity absorber was designed. Results showed that the standard deviation of irradiance and optical efficiency of optimized designed cavity absorber were $30528 \mathrm{~W} / \mathrm{m}^{2}$ and $89.23 \%$, respectively. Therefore, this study could offer some valuable references for designing the parabolic trough solar concentrator in the future.
\end{abstract}

\section{Introduction}

Concentrating solar power (CSP) system mainly consists of parabolic trough solar concentrator, linear Fresnel solar concentrator, compound parabolic solar concentrator, and solar tower. Sait et al. [1] investigated the optical and thermal analysis of different blocks of the solar power plant and they compared Fresnel arrays with parabolic trough solar concentrators. They found that the optical performance of Fresnel array was very close to that of parabolic trough solar concentrator, with similar values of maximum flux intensities. However, parabolic trough solar concentrator, as the most mature technology, has been intensively researched and its cost gradually reduced [2-13].

In addition, parabolic trough solar concentrator has been put into commercial operations in many countries [14]. Practically with the regulation of the tracking system, the collecting mirror of parabolic trough solar concentrator concentrates the solar rays to the absorber at the focal line and then the radiation energy converts into heat energy which transmits to the internal working medium of the absorber. Subsequently, it was confirmed that the absorber is the carrier of solar thermal conversion and its optical properties directly influenced the performance of the entire system [15].

There are two main types of absorbers for parabolic trough solar concentrator, namely, vacuum tube and cavity. Vacuum tube absorber has numerous advantages such as high efficiency and small heat loss. Nevertheless, it has some deficiencies such as technical difficulty, high cost, and gas leakage upon long-term running, while the cavity absorber could make up those shortages of vacuum tube absorber [1618]. Therefore, a group of scholars [19-24] have done a lot of studies on the structure of cavity absorbers in order to improve the cavity absorber properties, and they reported that the cavity absorbers with triangular structure had a high optical efficiency.

Based on the existing researches, a new theoretical analytical method for cavity absorber optical properties was proposed by using Monte Carlo Ray Tracing (MCRT) [25, 26] method. Furthermore, the distribution of solar rays on 


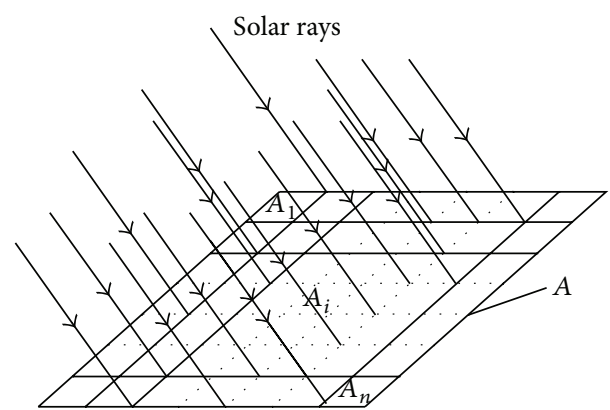

FIGURE 1: Schematic diagram of solar radiation received by absorber.

absorbing surface of triangular cavity absorber was carried out in a simulation experiment, and the optimized triangular cavity absorber was designed to provide high optical properties.

\section{Heat Loss Characteristics of Solar Energy Absorber Surface}

Assuming that there is a flat plate absorber as shown in Figure 1, the total area of the absorber is $A$ and the total radiation energy from the sun is $E$. When the irradiance of the absorber surface is uniform, $E$ can be estimated as

$$
E=I A \text {, }
$$

where $I$ is the direct irradiance. When the irradiance of the absorber surface changed to a nonuniform distribution, $E$ can be calculated as shown in

$$
E=\sum_{i=1}^{n} I_{i} A_{i}
$$

where the whole absorber area is divided into $n$ equal areas $A_{i}$ and $I_{i}$ is irradiance of each $A_{i}$, so

$$
\begin{aligned}
A_{1} & =A_{2}=\cdots=A_{i}=\cdots=A_{n}, \\
n A_{i} & =A, \\
n I & =\sum_{i=1}^{n} I_{i} .
\end{aligned}
$$

Obviously, the absorber surface has more irradiation, so the high surface temperature can be estimated as

$$
\begin{gathered}
T=f I, \\
T_{i}=f I_{i},
\end{gathered}
$$

where $T$ and $T_{i}$ are the surface temperatures of $A$ and $A_{i}$. $f$ is the proportionality coefficient, which is the function of absorber material, ambient environment, sky parameters, and so on.

According to the Stefan-Boltzmann law,

$$
\begin{aligned}
Q_{\text {unif }} & =\sigma \varepsilon A\left(T^{4}-T_{s}^{4}\right)=\sigma \varepsilon\left(A T^{4}-A T_{s}^{4}\right), \\
Q_{\text {non }} & =\sigma \varepsilon \sum_{i=1}^{n} A_{i}\left(T_{i}^{4}-T_{s}^{4}\right)=\sigma \varepsilon\left(\sum_{i=1}^{n} A_{i} T_{i}^{4}-A T_{s}^{4}\right),
\end{aligned}
$$

where $Q_{\text {unif }}$ and $Q_{\text {non }}$ are the heat losses of the absorber surface irradiance in uniform and nonuniform phases, respectively, $\sigma$ is Stefan-Boltzmann constant, and $\varepsilon$ is the emissivity of surface.

The relationship value between $Q_{\text {unif }}$ and $Q_{\text {non }}$ is analyzed as follows. According to the relationship between the arithmetic average and the root-mean-square value,

$$
\frac{T_{1}+T_{2}+\cdots+T_{n}}{n} \leq \sqrt{\frac{T_{1}^{2}+T_{2}^{2}+\cdots+T_{n}^{2}}{n}},
$$

when the equality held up as follows:

$$
T_{1}=T_{2}=\cdots=T_{i}=\cdots=T_{n} .
$$

By assuming that

$$
T_{i}=\alpha_{i} T, \quad 1 \leq i \leq n,
$$

where $\alpha_{i}$ is the proportionality coefficient, from formulae $((5)-(6))$

$$
n=\sum_{i=1}^{n} \alpha_{i}
$$

And then

$$
\begin{aligned}
& \frac{\alpha_{1} T+\alpha_{2} T+\cdots+\alpha_{n} T}{n} \\
& \quad \leq \sqrt{\frac{T^{2} \alpha_{1}^{2}+T^{2} \alpha_{2}^{2}+\cdots+T^{2} \alpha_{n}^{2}}{n}}, \\
& \frac{\alpha_{1}+\alpha_{2}+\cdots+\alpha_{n}}{n} \leq \sqrt{\frac{\alpha_{1}^{2}+\alpha_{2}^{2}+\cdots+\alpha_{n}^{2}}{n}}, \\
& \frac{\alpha_{1}^{2}+\alpha_{2}^{2}+\cdots+\alpha_{n}^{2}}{\alpha_{1}+\alpha_{2}+\cdots+\alpha_{n}} \geq 1, \\
& \frac{\alpha_{1}^{4}+\alpha_{2}^{4}+\cdots+\alpha_{n}^{4}}{\alpha_{1}^{2}+\alpha_{2}^{2}+\cdots+\alpha_{n}^{2}} \geq 1, \\
& \frac{\alpha_{1}^{4}+\alpha_{2}^{4}+\cdots+\alpha_{n}^{4}}{\alpha_{1}+\alpha_{2}+\cdots+\alpha_{n}} \geq 1, \\
& \frac{\alpha_{1}^{4} T^{4}+\alpha_{2}^{4} T^{4}+\cdots+\alpha_{n}^{4} T^{4}}{\alpha_{1} T^{4}+\alpha_{2} T^{4}+\cdots+\alpha_{n} T^{4}} \geq 1, \\
& \frac{A_{1} \alpha_{1}^{4} T^{4}+A_{2} \alpha_{2}^{4} T^{4}+\cdots+A_{n} \alpha_{n}^{4} T^{4}}{A_{i}\left(\alpha_{1} T^{4}+\alpha_{2} T^{4}+\cdots+\alpha_{n} T^{4}\right)} \geq 1, \\
& \frac{\sum_{i=1}^{n} A_{i} T_{i}^{4}}{A T^{4}} \geq 1 .
\end{aligned}
$$

Therefore, by comparison between (7), (8), and (20), it can be found that the irradiant heat loss of nonuniform distribution is higher than that of uniform distribution. 


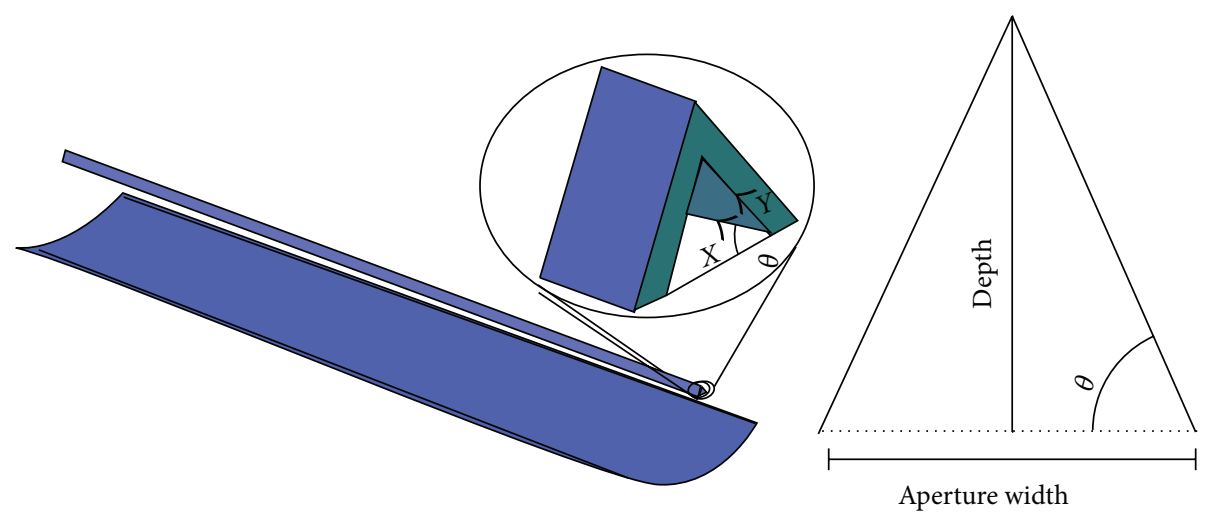

FIGURE 2: Optical properties simulation model of cavity absorber.

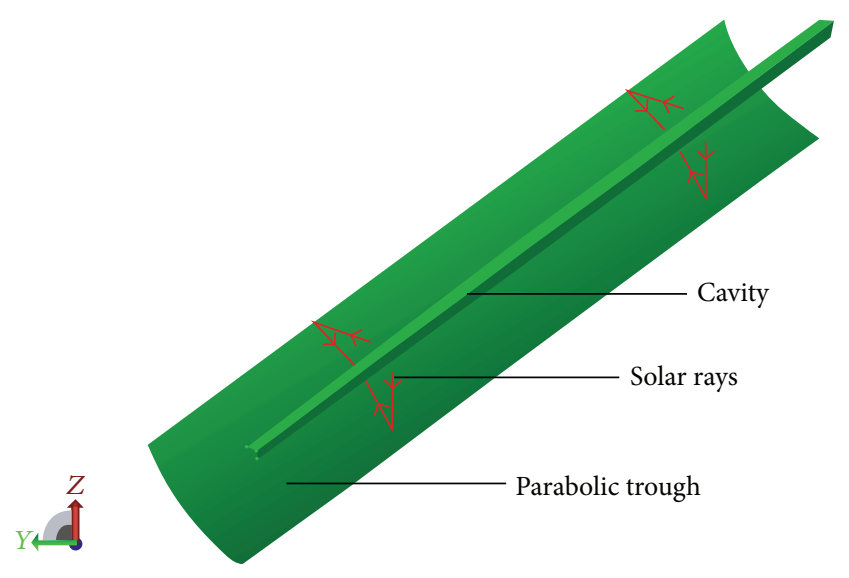

FIgURE 3: Optical properties simulated by TracePro.

\section{Simulation Model of Optical Properties}

Based on the MCRT, TracePro simulation experiment was carried out for the optical properties of triangular cavity absorber as shown in Figure 2. TracePro software was developed for system's optical design based on solid model drawing software of ACIS as the core. The TracePro has strong optical analysis and information transmission capacity and was widely applied in solar system, optics device design field, autolighting system, infrared optical imaging, indoor lighting system, optical thin film, and imaging system.

During the TracePro simulation process, the reflection, refraction, absorption, and transmission behaviors of solar rays were tracked and recorded one by one until the lights overflow the system or totally adsorbed and the solar ray tracing would be stopped at this time as shown in Figure 3. The solar rays from the sun of the parabolic trough solar concentrator were assumed as parallel. The surface of concentrating mirrors in the PTC was ideal without any mechanical or manufacturing error and the one-dimensional automatic tracking device in the PTC has no error or lag.

\section{Optical Properties of Absorber}

In order to analyze the properties of cavity absorber properly, optical efficiency and standard deviation of irradiance should be investigated. The optical efficiency demonstrates the ratio between the radiant energy received by cavity absorber and the direct radiant energy received by parabolic trough solar concentrator. Moreover, it is a key parameter for analyzing the optical properties of cavity absorber. Thereby, the optical efficiency can be estimated as shown in

$$
\eta=\frac{\iint_{C} I(x, y) \cos \theta d x d y}{S I}
$$

where $\eta$ is the optical efficiency of cavity absorber; $C$ is the area of absorption surface of cavity absorber; $I(x, y)$ is the irradiance distribution function of absorption surface of cavity absorber; $\theta$ is the included angle between the $y$ axis and the aperture of the triangular cavity absorber; $S$ is aperture area of parabolic trough solar concentrator.

The standard deviation of irradiance $D(I)$ is used to measure the evenness of energy distribution inside the cavity absorber. The cavity absorber at high standard deviation of irradiance has high fluctuation gradient and high heat loss. Furthermore, it has an important role for researching the heat loss of cavity absorber and $D(I)$ can be calculated as shown in

$$
D^{2}(I)=\iint_{C}[I(x, y)-E(I)]^{2} f(I) \cos \theta d x d y
$$

where $f(I)$ is probability density of $I(x, y) . E(I)$ is average of irradiance as shown in

$$
E(I)=\frac{1}{C} \iint_{C} I(x, y) d x d y .
$$

It is very difficult to determine the irradiance distribution function $I(x, y)$ and the probability density $f(I)$. Therefore, the irradiance of absorption surface of cavity absorber is a dispersed calculation in TracePro simulation experiment. 
TABLE 1: Simulation parameters for the optical properties of the cavity absorber.

\begin{tabular}{|c|c|c|c|}
\hline Parameter & $\begin{array}{l}\text { Aperture } \\
\text { width }\end{array}$ & $\begin{array}{l}\text { Depth-to-width } \\
\text { ratio }\end{array}$ & $\begin{array}{l}\text { Offset distance } \\
\text { from focus }\end{array}$ \\
\hline Aperture width & - & $45 \mathrm{~mm}$ & $45 \mathrm{~mm}$ \\
\hline $\begin{array}{l}\text { Depth-to-width } \\
\text { ratio }\end{array}$ & $3: 5$ & - & $3: 5$ \\
\hline $\begin{array}{l}\text { Offset distance from } \\
\text { focus }\end{array}$ & $0 \mathrm{~cm}$ & $0 \mathrm{~cm}$ & - \\
\hline
\end{tabular}

The calculation formulas for the optical efficiency, average of irradiance, and deviation of irradiance are shown in

$$
\begin{aligned}
\eta & =\frac{\sum_{i=1}^{n} \sum_{j=1}^{k} A_{i j} I_{i j}}{S I}, \\
E(I) & =\frac{\sum_{i=1}^{n} \sum_{j=1}^{k} I_{i j}}{n k}, \\
D^{2}(I) & =\frac{\sum_{i=1}^{n} \sum_{j=1}^{k}\left[I_{i j}-E(I)\right]^{2}}{n k},
\end{aligned}
$$

where $i$ and $j$ are the $x$-axis and $y$-axis direction of absorption surface, respectively, $n$ and $k$ are the total step number of $x$ axis and $y$-axis, respectively, $A_{i j}$ is the absorption area unit of absorption surface of cavity absorber, $I_{d}$ is the direct solar irradiance, and $I_{i j}$ is the irradiance of $A_{i j}$.

\section{Optical Properties Simulation}

The impacts on the optical properties caused by aperture width, depth-to-width ratio, and offset distance from focus of triangular cavity absorber were simulated. In the simulation experiment [12], the focal distance, the aperture width, and the aim angle of parabolic trough solar concentrator were $100 \mathrm{~cm}, 240 \mathrm{~cm}$, and $45^{\circ}$, respectively. The absorptivity, reflectance, and transmittance of the concentrating mirror in the parabolic trough solar concentrator were $6.5 \%$, $93.0 \%$, and $0.5 \%$, respectively. The solar direct irradiance was $1000 \mathrm{~W} / \mathrm{m}^{2}$. Cavity absorber has axial symmetry. Therefore, only half-cavity absorber has been analyzed for researching its optical properties. The parameters of the single factor simulation experiment are shown in Table 1.

5.1. Optical Properties Caused by the Aperture Width. The irradiance distribution of absorbing surface inside the cavity at different aperture width is shown in Figure 4. It can be seen that the absorbing surface irradiance of the triangular cavity absorber firstly increased and then decreased with the increasing of the distance away from the symmetry axis. In addition, the maximum irradiance gradually decreased with the increment of the aperture width from the symmetry axis. The phenomenon was very interesting and it was explained in latter paragraphs. The aperture widths of triangular cavity absorber were $30 \mathrm{~mm}, 45 \mathrm{~mm}, 60 \mathrm{~mm}, 75 \mathrm{~mm}$, and $90 \mathrm{~mm}$ whereas the maximum irradiances were $83066 \mathrm{~W} / \mathrm{m}^{2}$, $59418 \mathrm{~W} / \mathrm{m}^{2}, 48226 \mathrm{~W} / \mathrm{m}^{2}, 38249 \mathrm{~W} / \mathrm{m}^{2}$, and $32122 \mathrm{~W} / \mathrm{m}^{2}$

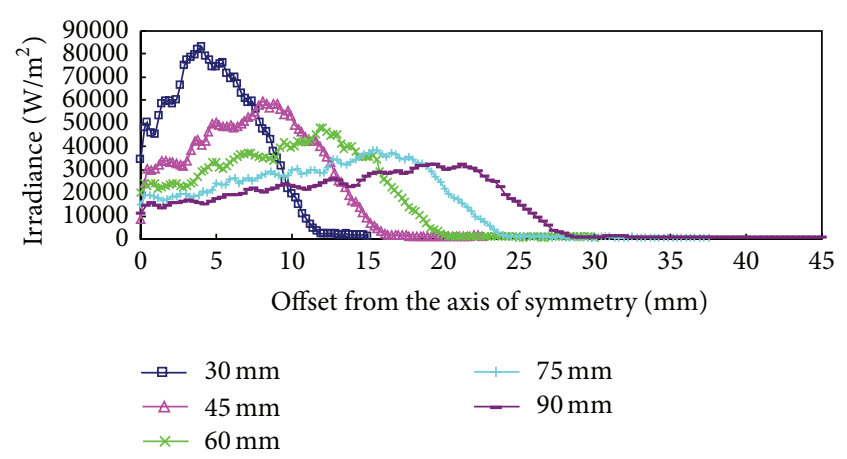

Figure 4: The irradiance distribution of absorbing surface at different aperture width.

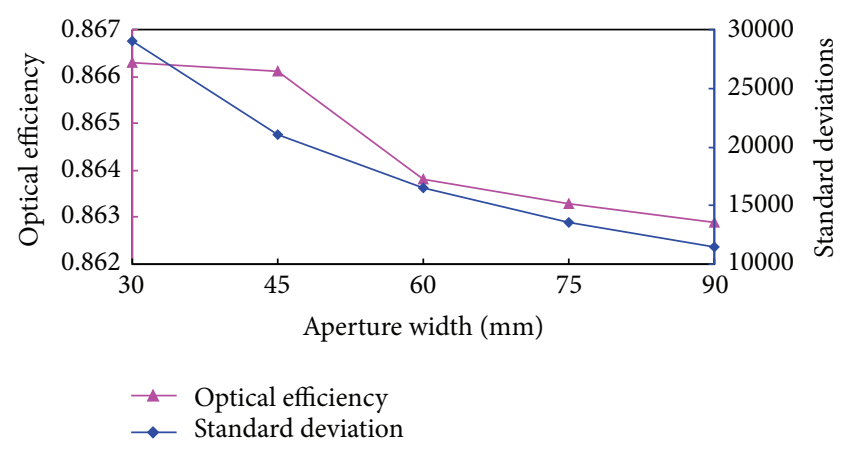

FIGURE 5: The optical properties of cavity at different aperture width.

with the positions away from the symmetry axis of $4.0 \mathrm{~mm}$, $8.1 \mathrm{~mm}, 12.0 \mathrm{~mm}, 15.4 \mathrm{~mm}$, and $19.1 \mathrm{~mm}$, respectively.

Figure 5 shows the effects of the aperture width of triangular cavity absorber on the optical properties. It was observed that the absorber's optical efficiency and the standard deviation of irradiance were decreasing with the increment of the aperture width. When the aperture widths of cavity absorber were $30 \mathrm{~mm}$ and $90 \mathrm{~mm}$, the optical efficiencies were $86.63 \%$ and $86.29 \%$, respectively. Meanwhile, the standard deviations of irradiances were $29037 \mathrm{~W} / \mathrm{m}^{2}$ and $11529 \mathrm{~W} / \mathrm{m}^{2}$, respectively, that is, because of the increment of the aperture width increasing the absorption area of cavity and reducing the radiation energy per area unit on absorbing surface. Therefore, the aperture width should not be very large. The large aperture width reduces the optical concentration ratio and increases the angle factor between absorbing surface and the ambient. In addition, it increases the heat losses of irradiance from the cavity absorber. However, actual parabolic trough solar concentrator has some errors such as the machining errors and tracing accuracy errors. The actual focal line width was bigger than that of ideal condition. Thereby, the width of the cavity absorber should not be very small.

5.2. Optical Properties Caused by the Depth-to-Width Ratio. The irradiance distribution of absorbing surface inside the cavity at different depth-to-width ratios is shown in Figure 6. It can be observed that the maximum irradiance decreased 


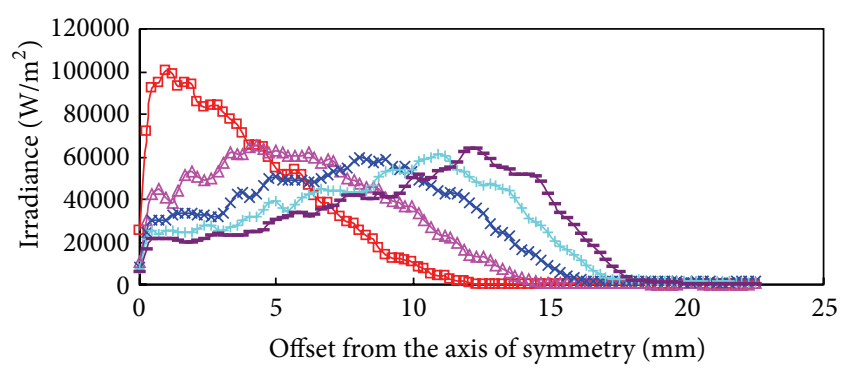

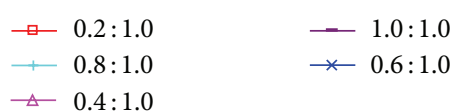

Figure 6: The irradiance distribution of absorbing surface at different depth-to-width ratio.

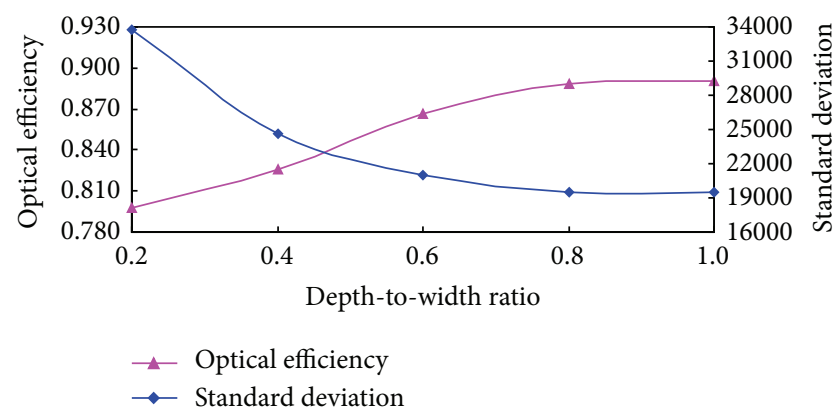

FIGURE 7: The optical properties of cavity at different depth-to-width ratio.

firstly and then increased with the increment of the depthto-width ratio of cavity absorber.

Figure 7 shows the effect of the depth-to-width ratios of triangular cavity absorber on the optical properties. It was found that the absorber's optical efficiency increases with the increment of the depth-to-width ratio. In contrast, the standard deviation of irradiance decreases with the increment of the depth-to-width ratio. The depth-to-width ratios were $0.2: 1.0$ and $1.0: 1.0$, the optical efficiencies were $79.72 \%$ and $89.03 \%$, and the standard deviations of irradiances were $33747 \mathrm{~W} / \mathrm{m}^{2}$ and $19502 \mathrm{~W} / \mathrm{m}^{2}$, respectively.

The solar rays can easily enter the inner of the cavity absorber with the increasing of cavity's depth-to-width ratios. Furthermore, the aperture of the cavity can detain the solar rays and it will be difficult to escape. Therefore, this was very beneficial for the irradiance uniformity of inner surface to improve the optical efficiency and decrease the standard deviation of the irradiance.

5.3. Optical Properties Caused by the Offset Distance from Focus. Figure 8 illustrates the irradiance distribution of absorbing surface inside the cavity at different offset distance from focus of the cavity (offset distance from focus was a negative value when the absorber was close to the trough system and a positive value on the contrary). It can be seen that the irradiance of absorbing surface increased firstly and then decreased with the increment of the distance

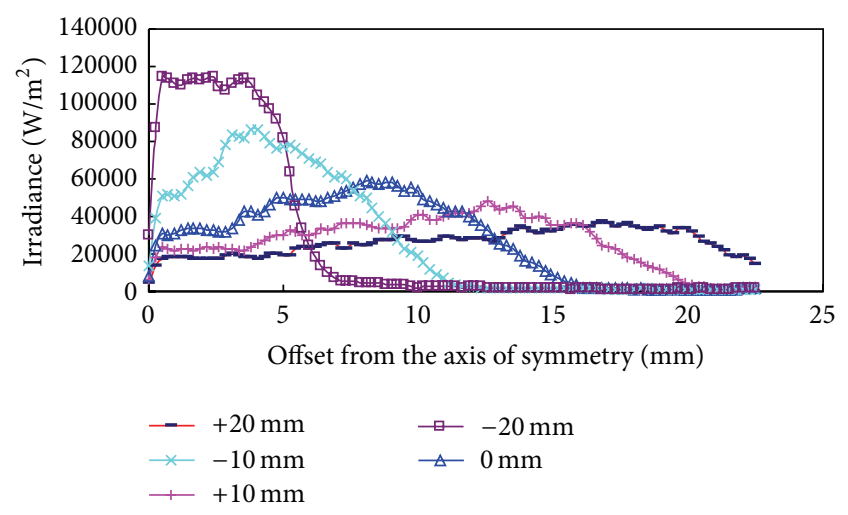

FIGURE 8: The irradiance distribution of absorbing surface for cavity at different focus offset distance.

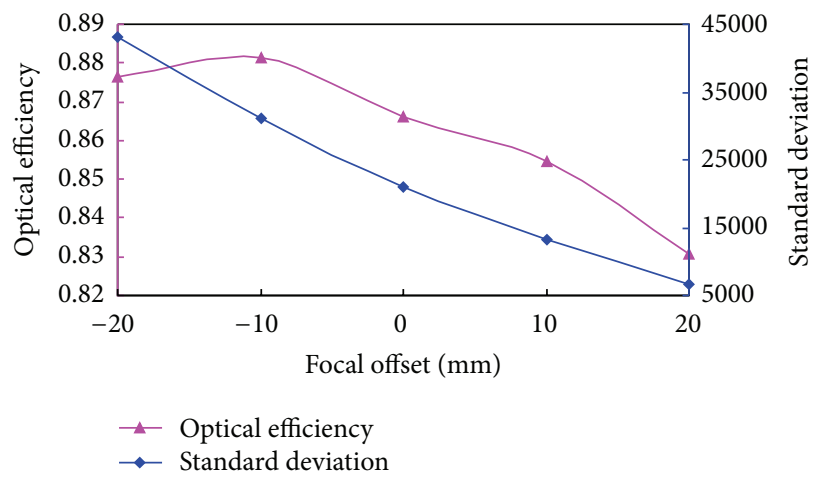

FIgURE 9: The optical properties of cavity at different focus offset.

from the symmetry axis. Moreover, the maximum irradiance decreased with increasing the distance from the symmetry axis and with the increment of the offset distance from focus.

The optical properties of the cavity could be changed at different offset distances from the focus as shown in Figure 9. It was clear that the absorber's standard deviation of irradiance decreased with the increment of the offset distances from the focus, while the optical efficiency increased firstly and then decreased with the increment of the offset distances from the focus. The offset distances from focus were $-20 \mathrm{~mm},-10 \mathrm{~mm}$, and $20 \mathrm{~mm}$, the optical efficiencies were $87.65 \%, 88.13 \%$, and $83.05 \%$, and the standard deviations of the irradiances were 43324,31058 , and 6741 , respectively. The parabolic trough solar concentrator concentrates the solar rays near its focal line and then the concentrated solar rays near the focal line can be absorbed and reflected by reaching the absorbing surface or it can be diffused. Therefore, by increasing the diffusing paths of concentrated rays, the solar energy will be more uniformity and the standard deviation of the irradiance will be decreased. It was also observed that when the offset distance from focus of cavity became more than zero, the diffused concentrated rays will be decreased, and it cannot reach the absorbing surface. Thereby, the optical efficiency and the standard deviation of the irradiance will be both decreased. 
TABLE 2: The parameters of the orthogonal experiments.

\begin{tabular}{lccc}
\hline Factor & \multicolumn{3}{c}{ Level } \\
& 1 & 2 & 3 \\
\hline A: aperture width/mm & 68 & 70 & 72 \\
B: depth-to-width ratio & $0.75: 1.00$ & $0.80: 1.00$ & $0.85: 1.00$ \\
C: offset distance $/ \mathrm{mm}$ & -15 & -10 & -5 \\
\hline
\end{tabular}

TABLE 3: The orthogonal experimental results of optical efficiency on cavity absorber.

\begin{tabular}{lcccc}
\hline Number & $A$ & $B$ & $C$ & $\begin{array}{c}\text { Optical } \\
\text { efficiency/\% }\end{array}$ \\
\hline 1 & 1 & 1 & 1 & 89.01 \\
2 & 1 & 2 & 2 & 89.15 \\
3 & 1 & 3 & 3 & 89.22 \\
4 & 2 & 1 & 2 & 88.97 \\
5 & 2 & 2 & 3 & 88.99 \\
6 & 2 & 3 & 1 & 89.33 \\
7 & 3 & 1 & 3 & 88.68 \\
8 & 3 & 2 & 1 & 89.03 \\
9 & 3 & 3 & 2 & 89.12 \\
Average 1 & 89.127 & 88.887 & 89.123 & \\
Average 2 & 89.097 & 89.057 & 89.080 & \\
Average 3 & 88.943 & 89.223 & 88.963 & \\
Range & 0.184 & 0.336 & 0.160 & \\
Primary and & & & $B>$ & \\
secondary & & & $A_{2} B_{3} C_{1}$ & \\
factors & & & & \\
Optimization & & &
\end{tabular}

In contrast, when the offset distance from focus of cavity became less than zero, the aperture of the cavity can detain the solar rays and it will be difficult to escape from the inner of cavity, and this resulted in improving the optical efficiency. In other words, when the offset distance from focus was too small, some solar rays could not reach the absorbing surface and the optical efficiency decreased. Subsequently, the cavity absorber was properly shifted downward from system's focal line position.

\section{Optimization}

In order to get the optimal optical properties of the cavity absorber, the structure and installation position of cavity absorber were properly designed according to the experimental results of each single factor on the optical properties of cavity absorber. The three-factors-three-levels orthogonal experiments L9 $\left(3^{3}\right)$ were designed and the parameters of the orthogonal experiments are shown in Table 2.

Table 3 shows the optical efficiency of orthogonal experiment. It was found that the depth-to-width ratio of cavity absorber was the most sensitive parameter on the optical properties. The range of optical efficiency was $0.336 \%$. The installation position of cavity absorber was relatively weak on the optical properties $(0.160 \%)$. Furthermore, the optical efficiency of the optimized cavity absorber was $89.33 \%$ when its aperture width, depth-to-width ratio, and offset distance were $70 \mathrm{~mm}, 0.85: 1.00$, and $-15 \mathrm{~mm}$, respectively.

The standard deviation of irradiance is shown in Table 4, and it can be seen that the standard deviation of irradiance was the most sensitive on the installation position. The range of the standard deviation of irradiance reached 5392. Moreover, the standard deviation of irradiance of optimized cavity absorber was 25257 when its aperture width, depth-towidth ratio, and offset distance were $72 \mathrm{~mm}, 0.75: 1.00$, and $-5 \mathrm{~mm}$, respectively.

The results of the structure parameters and installation position on cavity absorber by the orthogonal experiment on the optical efficiency and standard deviation of irradiance were different, which can be discussed as follows.

The influence of aperture width on the optical efficiency and standard deviation of irradiance were between depth-towidth ratio and offset distance, which can be seen from the primary and secondary factors as shown in Tables 3 and 4. Therefore, the aperture width can be set as $A_{2}$ for considering the properly optical efficiency.

The depth-to-width ratio of cavity absorber was the most sensitive on the optical efficiency. The larger depth-to-width ratio of cavity absorber was important to improve the optical efficiency. On the other hand, the larger depth-to-width ratio increased the cavity absorber's center of gravity and decreased the instability. Therefore, $B_{2}$ can be selected as the value of cavity absorber's depth-to-width ratio.

The solar rays could not be absorbed by cavity absorber for only one time but it could be absorbed by the inner of cavity absorber several times. It was found that the deep of cavity assisted the solar rays to enter the inner of cavity absorber, and the solar rays were detained by the aperture of the cavity absorber, which was important for the thermal performance of the cavity absorber. Consequently, $C_{1}$ can be selected as the value of cavity absorber's offset distance.

According to the above analysis, the optimized results were $A_{2} B_{2} C_{1}$ at the aperture width of $70 \mathrm{~mm}$, depth-to-width ratio of $0.80: 1.00$, and offset distance of $-15 \mathrm{~mm}$, respectively.

Results revealed that the standard deviation of irradiance and optical efficiency of optimized designed cavity absorber were 30528 and $89.23 \%$, respectively. The optical properties of the optimized designed cavity absorber are shown in Figure 9. It can be seen that the solar rays are concentrated inside the optimized designed cavity absorber, and then the concentrated solar rays are divergent and reach the absorbing surface of the cavity absorber. Furthermore, the reflected solar rays from the absorbing surface could reach the absorbing surface. Meanwhile, the solar rays could be absorbed by the absorbing surface of the cavity absorber several times, which is important to improve the photothermal performance of the optimized designed cavity absorber.

We can find in Figure 10 that the concentrated solar rays were concentrated at the aperture of cavity absorber reflect mirror. The concentrated solar rays met the absorber surface at the aperture which was absorbed by the cavity absorber; 
TABLE 4: The orthogonal experimental results of standard deviation of irradiance on cavity absorber.

\begin{tabular}{lcccc}
\hline Number & $A$ & $B$ & $C$ & Standard deviation of irradiance \\
\hline 1 & 1 & 1 & 1 & 32727 \\
2 & 1 & 2 & 2 & 30324 \\
3 & 1 & 3 & 3 & 26599 \\
4 & 2 & 1 & 2 & 29980 \\
5 & 2 & 2 & 3 & 26621 \\
6 & 2 & 3 & 1 & 31008 \\
7 & 3 & 1 & 3 & 25257 \\
8 & 3 & 2 & 1 & 30918 \\
9 & 3 & 3 & 2 & 29679 \\
Average 1 & 29883.333 & 29321.333 & 31551.000 & \\
Average 2 & 29203.000 & 29287.667 & 29994.333 & 26159.000 \\
Average 3 & 28618.000 & 29095.333 & 5392.000 & $C>A>B$ \\
Range & 1265.333 & 226.000 & $A_{3} B_{1} C_{3}$ & \\
Primary and secondary factors & & & & \\
Optimization & & & & \\
\hline
\end{tabular}

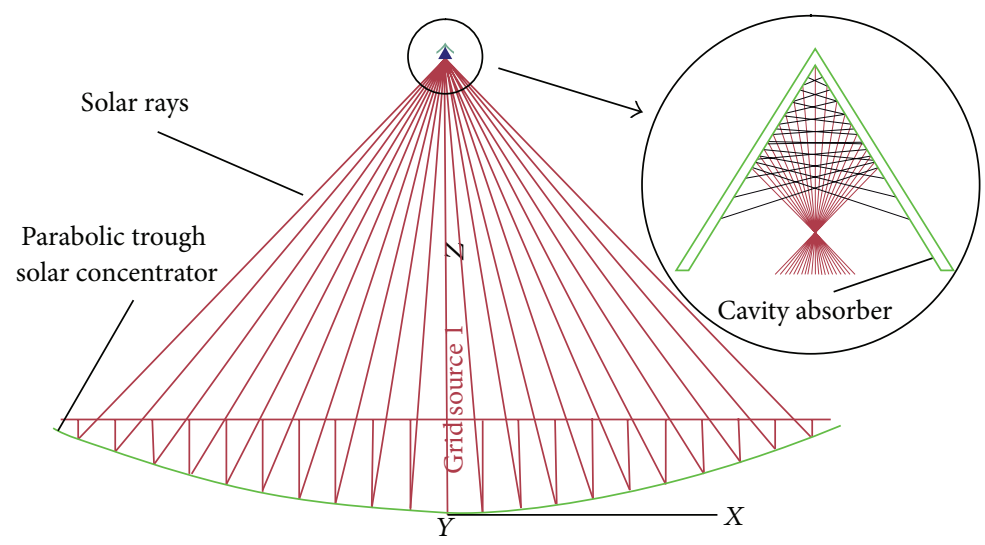

FIGURE 10: The optical properties of optimized designed cavity absorber.

otherwise the concentrated solar rays would be divergence and then divergence concentrated solar rays were arriving at the inner absorbing surface of cavity absorber. So the maximum irradiance achieved positions were not in the axis of symmetry of the cavity absorber in Figure 10.

\section{Conclusion}

The optical properties of triangular cavity absorber for parabolic trough solar concentrator were simulated and optimized. Furthermore, the optimized triangular cavity absorber was designed from the orthogonal experiment. Results illustrated that the standard deviation of irradiance and optical efficiency for the optimized designed cavity absorber were 30528 and $89.23 \%$, respectively. Results also revealed that the triangular cavity absorber's aperture width, depth-to-width ratio, and offset distance from focus under different conditions of appropriate values were beneficial to improve the optical properties. Therefore, it is recommended to select the aperture width of $70 \mathrm{~mm}$, depth-to-width ratio of $0.80: 1.00$, and offset distance of $-15 \mathrm{~mm}$, respectively.

\section{Nomenclature}

A: $\quad$ Total area of the absorber $\left(\mathrm{m}^{2}\right)$

E: $\quad$ All radiation energy from the sun (W)

I: $\quad$ Direct irradiance $\left(\mathrm{W} / \mathrm{m}^{2}\right)$

$T: \quad$ Temperature $(\mathrm{K})$

$\theta: \quad$ Inscribed cavity absorber $\left(^{\circ}\right)$

I: $\quad$ Direct solar irradiance $\left(\mathrm{W} / \mathrm{m}^{2}\right)$

$f: \quad$ Proportionality coefficient

Q: $\quad$ Heat loss $(\mathrm{W})$

$\alpha: \quad$ Proportionality coefficient

$\sigma: \quad$ Stefan-Boltzmann constant $\left(\mathrm{W} / \mathrm{m}^{2} \cdot \mathrm{K}^{4}\right)$

$\varepsilon: \quad$ The emissivity of surface

$\eta: \quad$ Optical efficiency of cavity absorber

$C: \quad$ Area of absorption surface $\left(\mathrm{m}^{2}\right)$

$I(x, y)$ : Irradiance distribution function $\left(\mathrm{W} / \mathrm{m}^{2}\right)$

$\theta: \quad$ The included angle $\left(^{\circ}\right)$

$S: \quad$ The aperture area of trough system $\left(\mathrm{m}^{2}\right)$

$E(I): \quad$ The average irradiance $\left(\mathrm{W} / \mathrm{m}^{2}\right)$

$D(I): \quad$ The deviation of irradiance

$G_{d}: \quad$ gray degree of the image. 


\section{Subscripts}

$i$ : $\quad$ Sequence number

$j$ : $\quad$ Sequence number

$n$ : $\quad$ Sequence number

$k$ : $\quad$ Sequence number

nuif: Uniform

non: Nonuniform.

\section{Conflict of Interests}

The authors declare that there is no conflict of interests regarding the publication of this paper.

\section{Acknowledgments}

The present study was supported by National Natural Science Foundation, China (Grant no. U1137605), the Individual Advanced Academic Prize in Yunnan Province, China (2013), the Basic Applied Research Foundation in Yunnan Province, China (Grant no. 2012FD018), and the National and International Scientific and Technological Cooperation Projects, China (Grant no. 2011DFA60460).

\section{References}

[1] H. H. Sait, J. M. Martinez-Val, R. Abbas, and J. Munoz-Anton, "Fresnel-based modular solar fields for performance/cost optimization in solar thermal power plants: a comparison with parabolic trough collectors," Applied Energy, vol. 141, pp. 175189, 2015.

[2] F. Wang, J. Tan, L. Ma, and C. Wang, "Effects of glass cover on heat flux distribution for tube receiver with parabolic trough collector system," Energy Conversion and Management, vol. 90, pp. 47-52, 2015.

[3] F. Chen, M. Li, P. Zhang, and X. Luo, "Thermal performance of a novel linear cavity absorber for parabolic trough solar concentrator," Energy Conversion and Management, vol. 90, no. 1, pp. 292-299, 2015.

[4] Y. Tian and C. Y. Zhao, "A review of solar collectors and thermal energy storage in solar thermal applications," Applied Energy, vol. 104, pp. 538-553, 2013.

[5] M. Wirz, J. Petit, A. Haselbacher, and A. Steinfeld, "Potential improvements in the optical and thermal efficiencies of parabolic trough concentrators," Solar Energy, vol. 107, pp. 398414, 2014

[6] R. Bader, A. Pedretti, M. Barbato, and A. Steinfeld, "An air-based corrugated cavity-receiver for solar parabolic trough concentrators," Applied Energy, vol. 138, pp. 337-345, 2015.

[7] X. Xiao, P. Zhang, D. D. Shao, and M. Li, "Experimental and numerical heat transfer analysis of a V-cavity absorber for linear parabolic trough solar collector," Energy Conversion and Management, vol. 86, pp. 49-59, 2014.

[8] Y. Wang, Q. Liu, J. Lei, and H. Jin, "Performance analysis of a parabolic trough solar collector with non-uniform solar flux conditions," International Journal of Heat and Mass Transfer, vol. 82, pp. 236-249, 2015.

[9] F.-Q. Wang, Y. Shuai, and H.-P. Tan, “Thermal analysis of solar cavity type receiver," Journal of Engineering Thermophysics, vol. 32, no. 5, pp. 843-846, 2011.
[10] C. S. Solanki, C. S. Sangani, D. Gunashekar, and G. Antony, "Enhanced heat dissipation of V-trough PV modules for better performance," Solar Energy Materials and Solar Cells, vol. 92, no. 12, pp. 1634-1638, 2008.

[11] T. Tao, Z. Hongfei, H. Kaiyan, and A. Mayere, "A new trough solar concentrator and its performance analysis," Solar Energy, vol. 85, no. 1, pp. 198-207, 2011.

[12] A. Fernández-García, E. Zarza, L. Valenzuela, and M. Pérez, "Parabolic-trough solar collectors and their applications," Renewable and Sustainable Energy Reviews, vol. 14, no. 7, pp. 1695-1721, 2010.

[13] H. Zhao, H. Liu, L. Jing et al., "Discrete spectral local measurement method for testing solar concentrators," International Journal of Photoenergy, vol. 2012, Article ID 290474, 8 pages, 2012.

[14] G. J. Gong, X. Y. Huang, J. Wang, and M. L. Hao, "An optimized model and test of the China's first high temperature parabolic trough solar receiver," Solar Energy, vol. 84, no. 12, pp. 22302245, 2010.

[15] P. L. Singh, R. M. Sarviya, and J. L. Bhagoria, "Thermal performance of linear Fresnel reflecting solar concentrator with trapezoidal cavity absorbers," Applied Energy, vol. 87, no. 2, pp. 541-550, 2010.

[16] Q. L. Chou, X. S. Ge, S. X. Chen, and Y. F. Li, "Numerical analysis of thermal characteristics of solar cavity receiver with absorber of a bundle of tubes," Acta Energiae Solaris Sinica, vol. 16, no. 2, pp. 21-28, 1995.

[17] L.-Y. Zhang, H. Zhai, Y.-J. Dai, and R.-Z. Wang, "Thermal analysis of cavity receiver for solar energy heat collector," Journal of Engineering Thermophysics, vol. 29, no. 9, pp. 14531457, 2008.

[18] T. Bai, Y. J. Dai, and R. Z. Wang, "Theoretical analysis of heat removal factor of linear concentrating solar collector using cavity receiver," Acta Energiae Solaris Sinica, vol. 32, no. 6, pp. 836-842, 2011.

[19] Q. L. Chou, X. S. Ge, Y. F. Li, S. X. Chen, and L. J. Liu, "The influence of environment condition on the heat efficiency of solar cavity receiver with absorber of a bundle of tubes," Acta Energiae Solaris Sinica, vol. 17, no. 1, pp. 81-86, 1996.

[20] Q. L. Chou, X. Q. Li, G. Xu, and X. S. Ge, "The experiment validation of the dynamic simulation model for 3-dimensions thermal network of medium temperature solar collector system," Acta Energiae Solaris Sinic, vol. 20, no. 2, pp. 196-199, 1999.

[21] D. A. Boyd, R. Gajewski, and R. Swift, "A cylindrical blackbody solar energy receiver," Solar Energy, vol. 18, no. 5, pp. 395-401, 1976.

[22] Q. L. Chou, H. Ye, X. S. Ge et al., "Calculation of influence of optical properties of parabolic mirror and receiver window on thermal behavior of solar energy collector system with emulation mold of 4-dimensions thermal network numerical analysis of thermal characteristics of solar cavity receiver with absorber of a bundle of tubes," Acta Energiae Solaris Sinica, vol. 18, no. 3, pp. 307-313, 1997.

[23] O. A. Barra and L. Franceschi, "The parabolic trough plants using black body receivers: experimental and theoretical analyses," Solar Energy, vol. 28, no. 2, pp. 163-171, 1982.

[24] H. Zhai, Theoretical and experimental investigation of linear concentrating solar collector with cavity [Ph.D. thesis], Shanghai Jiao Tong University, Shanghai, China, 2009.

[25] Z. D. Cheng, Y. L. He, F. Q. Cui, R. J. Xu, and Y. B. Tao, "Numerical simulation of a parabolic trough solar collector with 
nonuniform solar flux conditions by coupling FVM and MCRT method," Solar Energy, vol. 86, no. 6, pp. 1770-1784, 2012.

[26] Y.-L. He, J. Xiao, Z.-D. Cheng, and Y.-B. Tao, "A MCRT and FVM coupled simulation method for energy conversion process in parabolic trough solar collector," Renewable Energy, vol. 36, no. 3, pp. 976-985, 2011. 

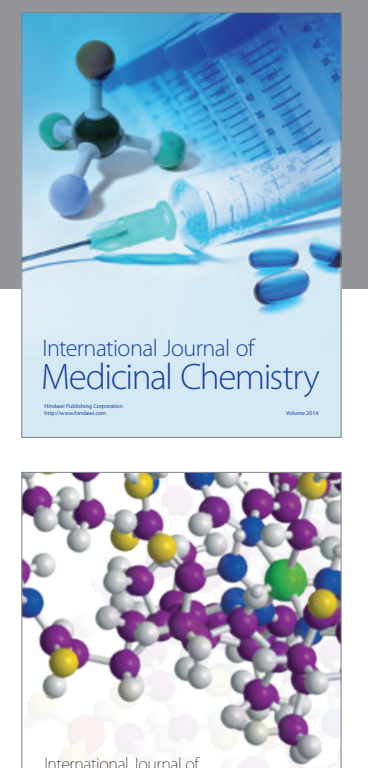

\section{Carbohydrate} Chemistry

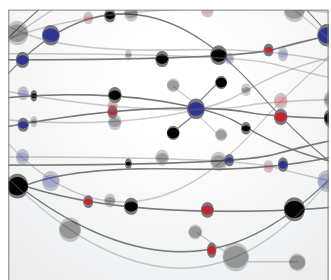

The Scientific World Journal
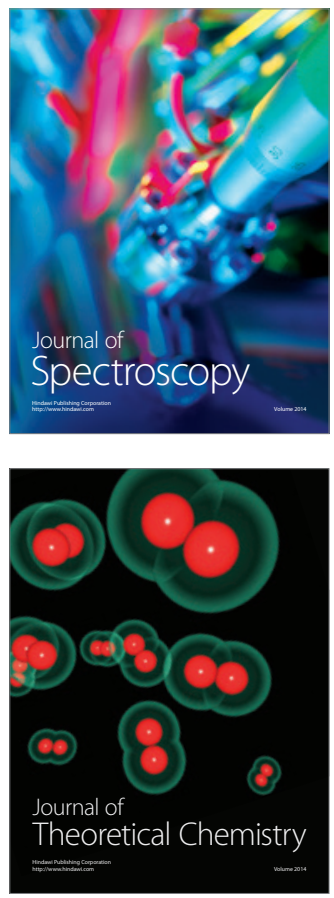
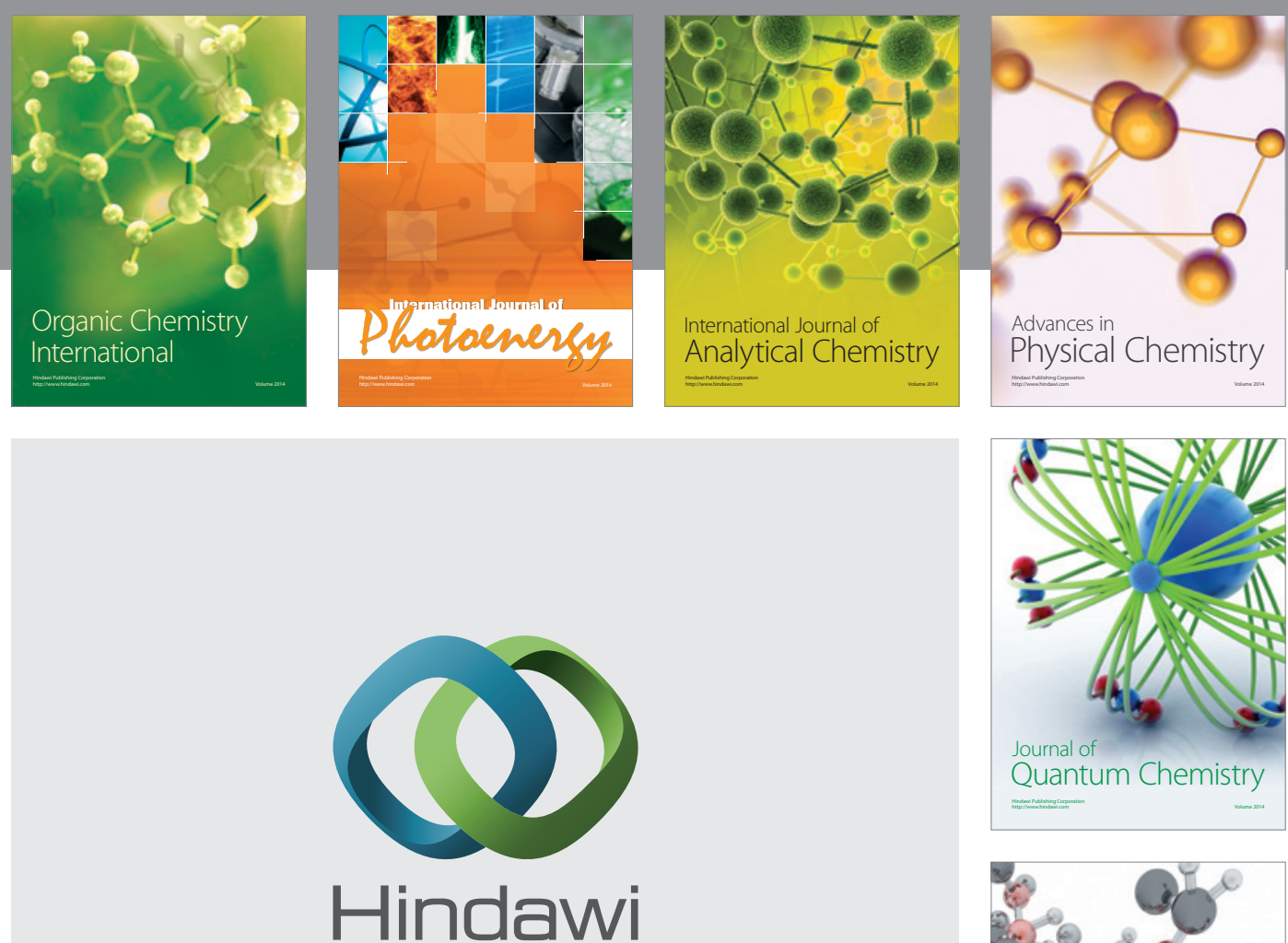

Submit your manuscripts at

http://www.hindawi.com

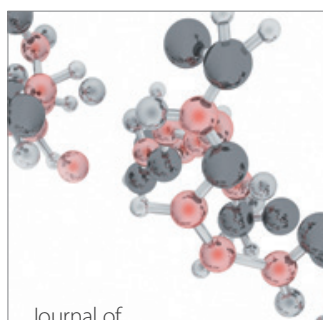

Analytical Methods

in Chemistry

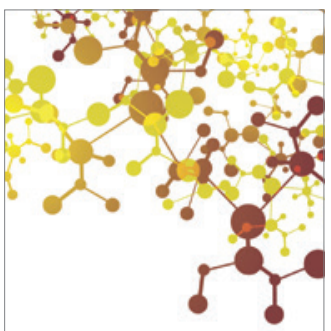

Journal of

Applied Chemistry

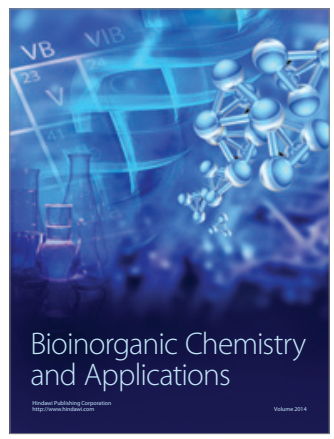

Inorganic Chemistry
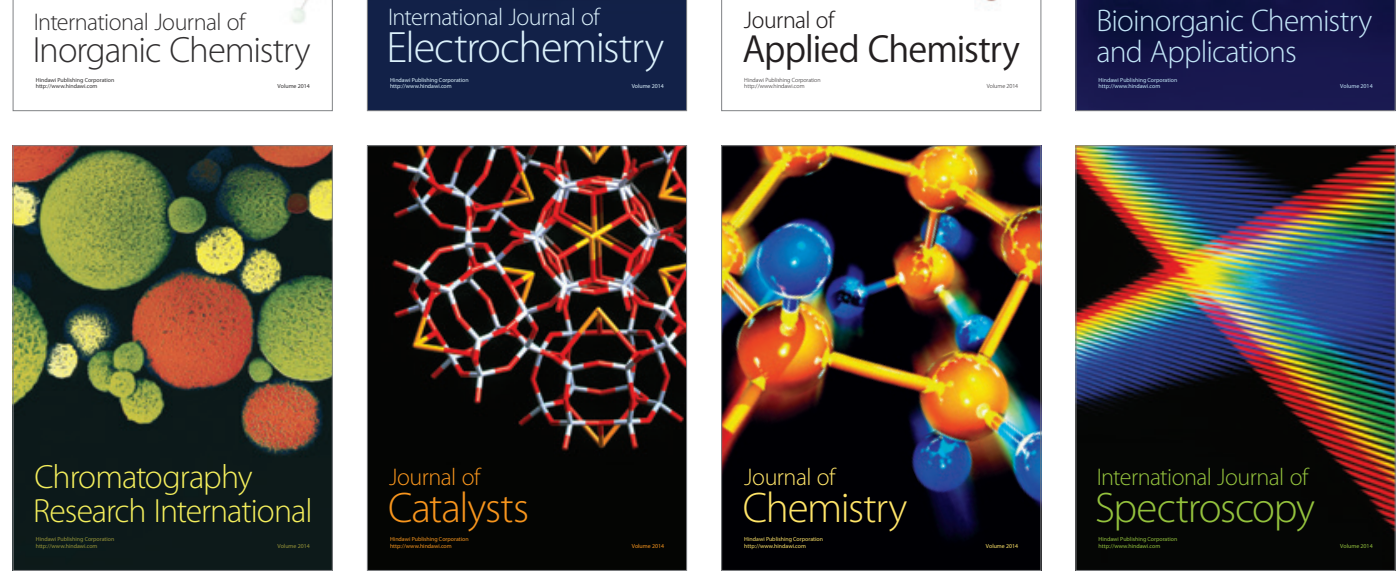